\title{
Low-threshold continuous-wave operation of quantum-cascade lasers grown by metalorganic vapor phase epitaxy
}

\section{Citation}

Troccoli, Mariano, David Bour, Scott Corzine, Gloria Höfler, Ashish Tandon, Dan Mars, David J. Smith, Laurent Diehl, and Federico Capasso. 2004. "Low-Threshold Continuous-Wave Operation of Quantum-Cascade Lasers Grown by Metalorganic Vapor Phase Epitaxy." Applied Physics Letters 85 (24): 5842-44. https://doi.org/10.1063/1.1834715.

\section{Permanent link}

http://nrs.harvard.edu/urn-3:HUL.InstRepos:41371374

\section{Terms of Use}

This article was downloaded from Harvard University's DASH repository, and is made available under the terms and conditions applicable to Other Posted Material, as set forth at http:// nrs.harvard.edu/urn-3:HUL.InstRepos:dash.current.terms-of-use\#LAA

\section{Share Your Story}

The Harvard community has made this article openly available.

Please share how this access benefits you. Submit a story.

\section{Accessibility}




\title{
Low-threshold continuous-wave operation of quantum-cascade lasers grown by metalorganic vapor phase epitaxy
}

\author{
Mariano Troccolia) \\ Division of Engineering and Applied Sciences, Harvard University, Cambridge, Massachusetts 02138 \\ David Bour, Scott Corzine, Gloria Höfler, Ashish Tandon, and Dan Mars \\ Agilent Labs, 3500 Deer Creek Road, Palo Alto, California 94304 \\ David J. Smith \\ Department of Physics and Astronomy and Center for Solid State Science, Arizona State University, Tempe, \\ Arizona 85287-1704 \\ Laurent Diehl and Federico Capasso \\ Division of Engineering and Applied Sciences, Harvard University, Cambridge, Massachusetts 02138
}

(Received 17 August 2004; accepted 18 October 2004)

\begin{abstract}
We report on the realization of InGaAs/InAlAs quantum-cascade lasers grown by metalorganic vapor phase epitaxy operating in continuous wave with low-threshold current densities at temperatures as high as $188 \mathrm{~K}$. Threshold current densities of $950 \mathrm{~A} / \mathrm{cm}^{2}$ and output powers of $125 \mathrm{~mW}$ are measured at $80 \mathrm{~K}$, while $3 \mathrm{~mW}$ of continuous output power are measured at $180 \mathrm{~K}$, with a threshold of $2.5 \mathrm{kA} / \mathrm{cm}^{2}$. In pulsed mode, peak output powers of more than $0.4 \mathrm{~W}$ were obtained at $80 \mathrm{~K}$ and of $160 \mathrm{~mW}$ at $300 \mathrm{~K}$ with thresholds of $700 \mathrm{~A} / \mathrm{cm}^{2}$ and $2.75 \mathrm{kA} / \mathrm{cm}^{2}$, respectively. (C) 2004 American Institute of Physics. [DOI: 10.1063/1.1834715]
\end{abstract}

Quantum cascade (QC) lasers ${ }^{1,2}$ have been grown so far preferentially by molecular beam epitaxy (MBE), a growth technique that has brought very promising results for the applications of these mid- to far-infrared sources. Room temperature (RT), cw operation has been achieved ${ }^{3}$ and recent improvements have demonstrated high powers and low thresholds for RT operation. ${ }^{4}$ However, an important step in the development of quantum cascade laser technology is the capability to grow high-quality material by metalorganic vapor phase epitaxy (MOVPE), enabling low cost and high yield production of lasers working at room temperature with high powers. MOVPE-grown quantum cascade lasers have been operated in pulsed mode and had high thresholds and low powers at RT. ${ }^{5,6}$ This letter presents the $\mathrm{cw}$ operation of MOVPE-grown quantum-cascade lasers up to temperatures as high as $188 \mathrm{~K}$ and delivering more than $125 \mathrm{~mW}$ of output power at $80 \mathrm{~K}$, with threshold current densities of $750 \mathrm{~A} / \mathrm{cm}^{2}$. RT $(T=300 \mathrm{~K})$ operation is also demonstrated in pulsed mode, with peak powers of $160 \mathrm{~mW}$ and thresholds of $2.75 \mathrm{kA} / \mathrm{cm}^{2}$, while peak powers of $0.45 \mathrm{~W}$ are obtained at $80 \mathrm{~K}$.

We have grown a 30-stage AlInAs/GaInAs QC laser structure lattice matched to the InP substrate, similar to that described by Gmachl et al., ${ }^{7}$ by conventional, low-pressure (76 Torr) MOVPE. This laser design provides state-of-theart performance and has been used in many sensing applications. ${ }^{8}$ Our Thomas Swan reactor incorporates a purged and pressure-balanced switching manifold and a close-spaced showerhead injector. Similar to the conditions employed by Green et al., ${ }^{6}$ the growth rate for the quantumcascade active region was set very low $(0.1 \mathrm{~nm} / \mathrm{s})$, and $5 \mathrm{~s}$ growth stops were employed at all interfaces. The remainder of the structure was grown at approximately five times this rate. Precursors include trimethylindium, triethylgallium (for the slow-grown QC structure only), trimethylgallium (for the

\footnotetext{
${ }^{a)}$ Electronic mail: troccoli@deas.harvard.edu
}

InGaAs separate confinement heterostructure), trimethylaluminum, arsine, phosphine, and disilane $\left(0.01 \%\right.$ in $\left.\mathrm{H}_{2}\right)$ for $n$-type doping. The samples were grown at a temperature of $650{ }^{\circ} \mathrm{C}$ (calibrated by the eutectic temperature of $\mathrm{Al}-\mathrm{Si}$ ) on (001)-oriented InP:S $\left(n=3 \times 10^{18} \mathrm{~cm}^{-3}\right)$ substrates. To avoid excessive free-carrier loss associated with the high doping in the substrate, a relatively thick $(3 \mu \mathrm{m})$ low-doped $n$-type InP:Si $\left(n=2 \times 10^{17} \mathrm{~cm}^{-3}\right)$ cladding layer was grown before the 0.45 - $\mu$ m-thick, $n=5 \times 10^{16} \mathrm{~cm}^{-3}$ doped, InGaAs waveguide core layers that enclose the quantum cascade active region. Likewise, the $\mathrm{InP}$ upper cladding layer is similarly thick, to minimize the loss arising from the top layer, highly doped for plasmon-enhanced confinement of the laser mode (500 nm InP:Si with $n=5 \times 10^{18} \mathrm{~cm}^{-3}$ ), and from the top metal contact. The ability to grow such thick InP cladding layers is a primary advantage of MOVPE. The quantumcascade active region is nominally identical to that reported by Gmachl et al. ${ }^{7}$ To reduce the series resistance, the interfaces between the InGaAs waveguide core layers and the InP cladding layers comprise $30 \mathrm{~nm}$ step-graded InGaAsP.

The measured (004) double-crystal x-ray diffraction spectrum of the QC laser wafer is shown in Fig. 1(a), in comparison to the simulated spectrum (bottom). Satellite reflections are clearly visible, indicating the presence of a periodic structure. The spacing of the satellites indicates a periodicity of about $42 \mathrm{~nm}$, corresponding to the thickness of each QC stage. This is slightly thinner than the designed stage thickness of $44.3 \mathrm{~nm}$. This difference could be an indication of a systematic error, where each layer forming the QC stack is about 5\% too thin. To further investigate the interface quality, we performed transmission electron microscopy (TEM) of the active region as shown in Fig. 1(b). Cross-section samples were prepared for TEM examination by standard mechanical polishing, dimpling, and final ionbeam milling to perforation. Observations were made with a JEM-4000EX high-resolution electron microscope operated at $400 \mathrm{keV}$. Samples were viewed in bright-field mode at or 


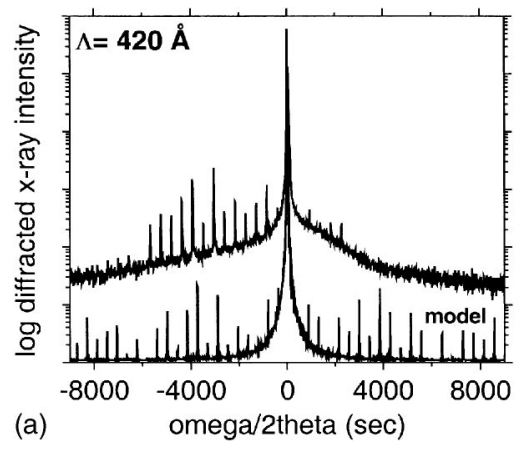

(b)

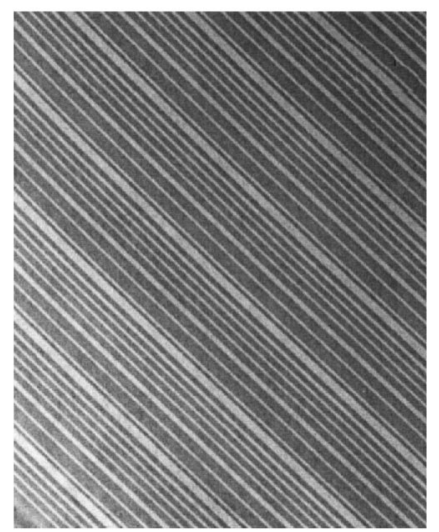

FIG. 1. (a) Double-crystal $\mathrm{x}$-ray diffraction spectra (measured-top, simulated-bottom) of the measured QC laser wafer and (b) TEM bright-field image of a section of the active region. $\mathrm{Ga}_{0.47} \mathrm{In}_{0.53} \mathrm{As}$ layers are dark and $\mathrm{Al}_{0.48} \mathrm{In}_{0.52} \mathrm{As}$ layers are light.

close to the common [110]-type projection. Clearest differentiation between the various layers was achieved using a small objective aperture. The TEM image confirms the good quality of the interface abruptness that can be achieved by MOVPE and the shorter than expected periodicity of the active region.

The lasers were fabricated as ridge waveguide structures, wet-etched down to the lower InP layer, and with a 350-nm-thick $\mathrm{Si}_{3} \mathrm{~N}_{4}$ insulating layer deposited on the lateral walls of the waveguide. A Ti(30 nm)/ $\mathrm{Au}(350 \mathrm{~nm})$ top contact and a Ge(12 nm)/Au(27 nm)/Ag(50 nm)/Au(250 nm) back contact were deposited and the devices were indium soldered from the substrate side onto a Ni/Au-plated copper block. The samples were then mounted in a liquid- $\mathrm{N}_{2}$ flow cryostat for the low-temperature measurements.

Figure 2(a) shows the spectral measurements at 80 and $300 \mathrm{~K}$ for lasers operated in pulsed mode, with $100 \mathrm{~ns}$ current pulses at a repetition rate of $11 \mathrm{kHz}$. A Fouriertransform infrared spectrometer equipped with a deuterated triglycine sulfate detector was employed for these measurements. The room-temperature emission is at $7.6 \mu \mathrm{m}$, blueshifted by $6 \%$ relative to the original design at $8.1 \mu \mathrm{m} .^{7}$ This is possibly explained by the X-ray and TEM measurements that showed a $5 \%$ reduction in the layer thickness, which would likely induce a shift of the emission toward higher energies. Further calibration of the growth procedure should easily correct for this discrepancy. The voltage-current and output power-current characteristics for the lasers operated in pulsed mode at 80 and $300 \mathrm{~K}$ are also shown in Fig. 2(b). At the lowest temperature, peak powers of $0.45 \mathrm{~W}$ are attained, with threshold currents of $300 \mathrm{~mA}\left(700 \mathrm{~A} / \mathrm{cm}^{2}\right)$, while at $300 \mathrm{~K}$ the maximum power output is of $160 \mathrm{~mW}$ with thresholds of $1.1 \mathrm{~A}\left(2.75 \mathrm{kA} / \mathrm{cm}^{2}\right)$. The power was Downloaded 10 Dec 2004 to 128.103.60.225. Redistribution subject
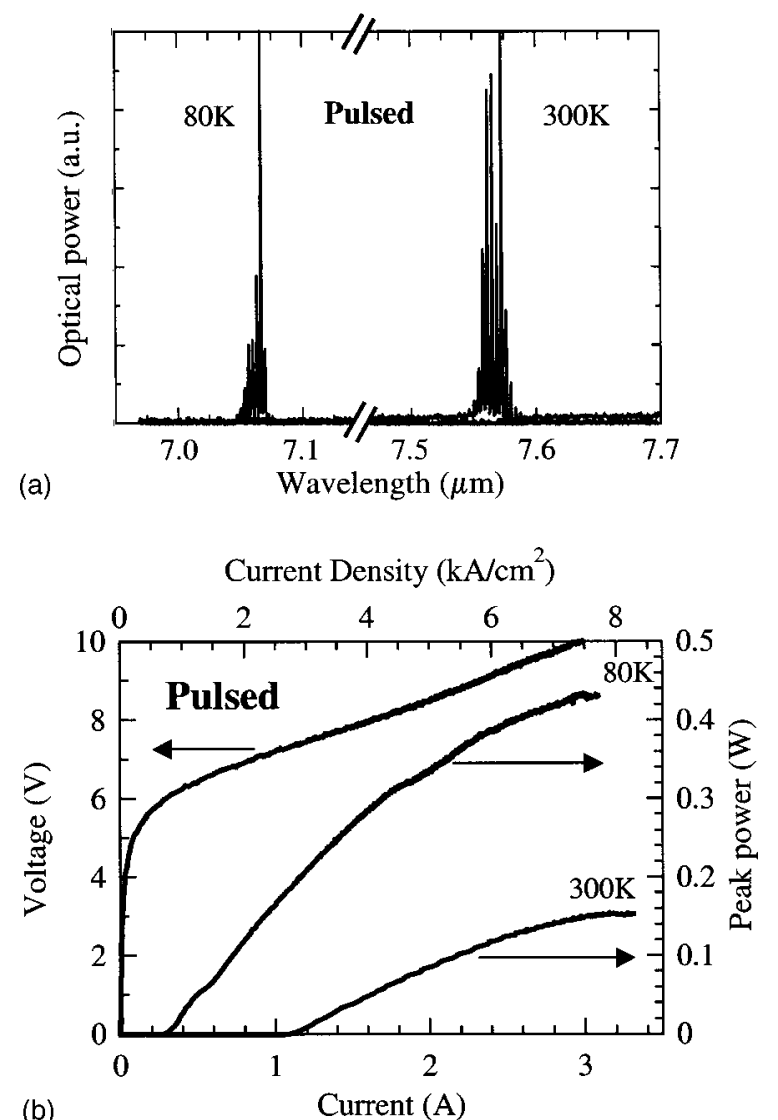

FIG. 2. (a) Pulsed operation emission spectra from the QC laser at temperatures of 80 and $300 \mathrm{~K}$ and currents of 0.3 and $1.1 \mathrm{~A}$, respectively. The Fabry-Perot modes are clearly distinguishable. (b) Voltage-current $(I-V)$ and light-current $(L-I)$ characteristics of the same laser operated in pulsed mode with a duty cycle of $0.05 \%$. The $I-V$ shown is the one measured at $80 \mathrm{~K}$ together with the corresponding $L-I$, while only the $L-I$ characteristic is shown for the room temperature operation for clarity reasons.

measured with a calibrated room temperature $\mathrm{HgCdTe}$ photodetector.

The cw-operation data are shown in Figs. 3 and 4. The spectra acquired from a cw-operated 14- $\mu \mathrm{m}$-wide laser close to threshold are shown in Fig. 3(a). Lasing from 80 to $180 \mathrm{~K}$ is observed and in most cases the spectra show single mode operation with almost $30 \mathrm{~dB}$ of side mode suppression ratio [see Fig. 3(a), inset]. Well above threshold the spectra become multimode, as shown in Fig. 3(b), where typical emission spectra acquired just above threshold $(I=350 \mathrm{~mA})$ and at about twice the threshold current $(I=600 \mathrm{~mA})$ are shown together with the corresponding light-current characteristic of the device measured at a heat sink temperature of $80 \mathrm{~K}$.

The cw power-current and voltage-current characteristics are displayed in Fig. 4(a). At $80 \mathrm{~K}$, threshold currents of $0.3 \mathrm{~A}\left(950 \mathrm{~A} / \mathrm{cm}^{2}\right)$ and a slope efficiency of $135 \mathrm{~mW} / \mathrm{A}$ have been recorded, and $\mathrm{cW}$ operation is observed up to $180 \mathrm{~K}$ with thresholds of $0.9 \mathrm{~A}$ and a maximum power of $3 \mathrm{~mW}$. By coating the back facet of this same sample, we were able to reduce the threshold current by $25 \%$ and increase continuous wave operation up to $188 \mathrm{~K}$. From wider laser stripes (20 $\mu \mathrm{m}$ wide, $2 \mathrm{~mm}$ long) higher powers of $125 \mathrm{~mW}$ were obtained at $80 \mathrm{~K}$ with a slope efficiency of $285 \mathrm{~mW} / \mathrm{A}$, but $\mathrm{cw}$ operation was observed only up to $140 \mathrm{~K}$ due to the larger amount of heat that must be dissipated [Fig. 4(b)]. The differential resistance value derived from the cw voltage-current measurements at $80 \mathrm{~K}$ is plotted to AIP license or copyright, see http://apl.aip.org/apl/copyright.jsp 

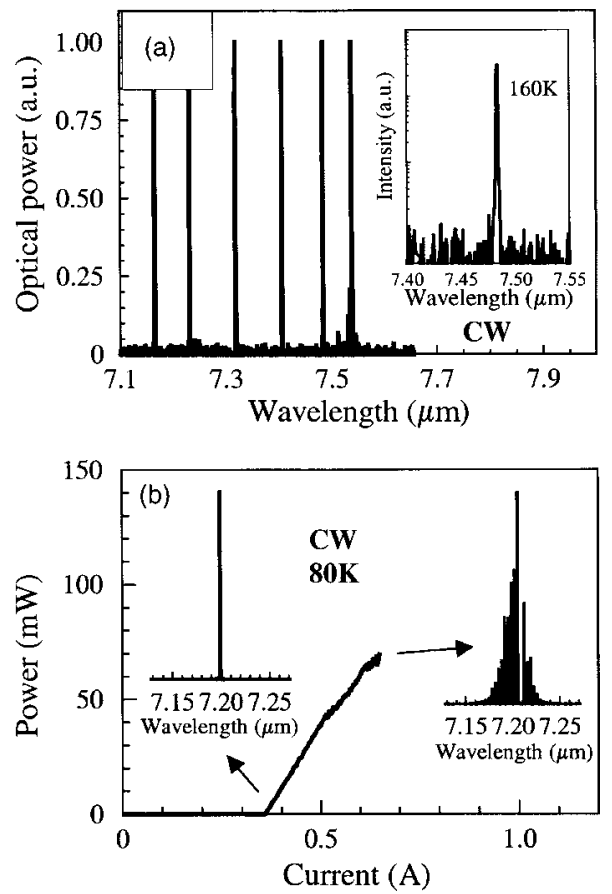

FIG. 3. (a) Normalized continuous wave spectra measured from a $14-\mu \mathrm{m}$-wide laser stripe at temperatures of (from left to right) $80,100,120$, $140,160,180 \mathrm{~K}$ and currents of $0.35,0.36,0.4,0.5,0.7$, and $0.95 \mathrm{~A}$, respectively. Inset: Logarithmic scale plot of the $160 \mathrm{~K}$ spectrum, showing a side mode suppression of almost $30 \mathrm{~dB}$. (b) Comparison of typical cw emission spectra at currents close to threshold $(I=0.35 \mathrm{~A}$, left side $)$ and at about twice the threshold current ( $I=0.6 \mathrm{~A}$, right side), shown together with the relative light-current characteristic for a device measured at $80 \mathrm{~K}$.

in the inset of Fig. 4(a), and it can be noticed that at around $0.3 \mathrm{~A}$, corresponding to the laser threshold current, there is a sudden lowering of the differential resistance. This effect is commonly observed in MBE-grown QC lasers as well and is due to the change in lifetime of the laser transition at threshold. 9

Devices fabricated from wafers grown in different conditions were also characterized. We compared the data shown here with those obtained from samples grown at higher rates (0.5 instead of $0.1 \mathrm{~nm} / \mathrm{s})$ and with samples grown at a low rate but without growth stops at the interface between different materials. The performances in both cases were not as good as the ones presented here, with an increase of $30 \%$ in the threshold and a decrease of $50 \%$ in the slope efficiency for the samples without growth stops and a low growth rate, and an increase of $60 \%$ in threshold for the sample grown at higher rate. ${ }^{10}$

In conclusion, we presented emission data from MOVPE-grown QC lasers that demonstrate performances that start to be competitive with state-of-the-art MBE-grown devices, an encouraging step toward a wider application of this technology. The most important advantages of the application of MOVPE technology to the growth of QC lasers reside in the possibility of growing very thick layers (typically cladding and burying layers) and in the possibility to grow at high temperatures, thus promoting smoother surfaces. Moreover, MOVPE is typically more stable over long growth times (typical of QC lasers) and allows one to grow continuously graded semiconductor alloys. Finally, higher growth rates are possible, but it still remains to be proven that they are viable for the production of QC lasers. The main drawback of MOVPE with respect to MBE is that the
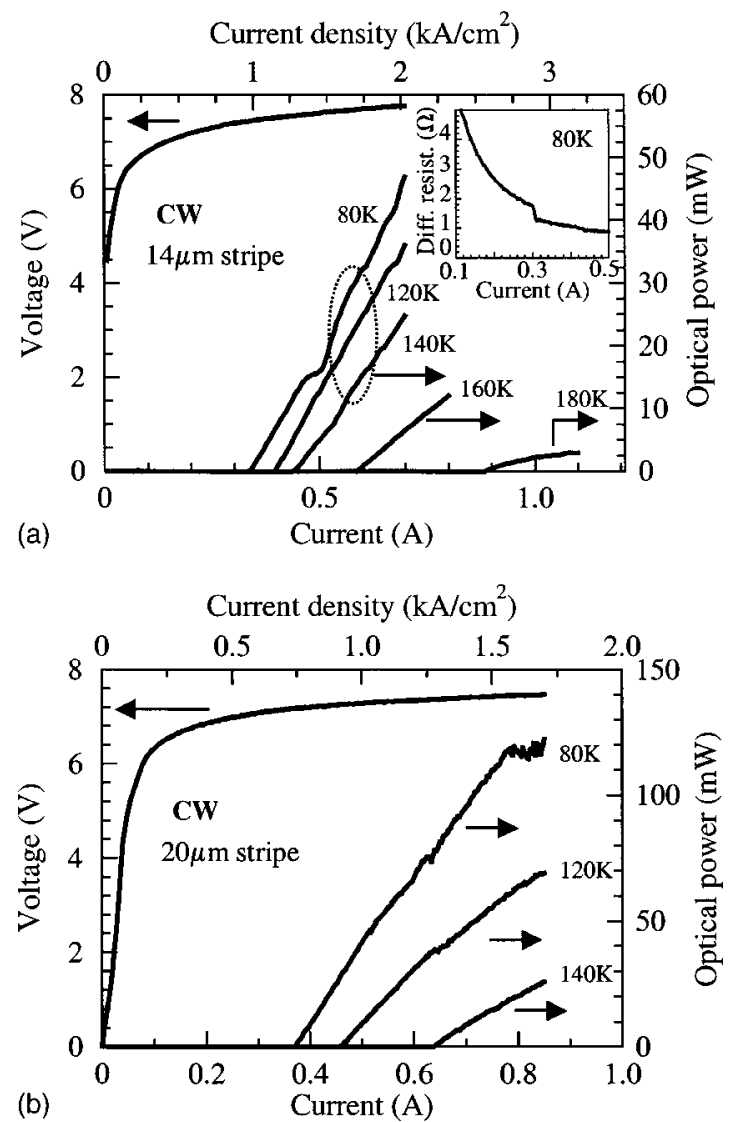

FIG. 4. (a) cw $I-V$ and optical power-current $(L-I)$ characteristics of a 14- $\mu \mathrm{m}$-wide, 2-mm-long, laser stripe measured at temperatures of $80 \mathrm{~K}$ ( $I-V$ and leftmost $L-I), 120,140,160$, and $180 \mathrm{~K}$, from left to right. Inset: differential resistance derived from the $I-V$ curve, where a dip is clearly visible at the current corresponding to the laser threshold at $80 \mathrm{~K}$. (b) cw $I-V$ and $L-I$ measurements for a 20- $\mu \mathrm{m}$-wide, 2-mm-long laser ridge waveguide. The $L-I$ curves were measured at temperatures of (from left to right): $80,120,140 \mathrm{~K}$, while the $I-V$ shown is the one recorded at $80 \mathrm{~K}$.

formation of abrupt interfaces can be more challenging, a characteristic that may be important but not obviously related to the laser performances. The optimization of device packaging by use of InP re-growth and thick gold plating on the top contact combined with mounting the device epitaxialside down on the heat sink would improve the performances even further and bring the lasers close to room temperature continuous operation.

${ }^{1}$ F. Capasso, R. Paiella, R. Martini, R. Colombelli, C. Gmachl, T. L. Myers, M. S. Taubman, R. M. Williams, C. G. Bethea, K. Unterrainer, H. Y. Hwang, D. L. Sivco, A. Y. Cho, A. M. Sergent, H. C. Liu, and E. A. Whittaker, IEEE J. Quantum Electron. 38, 511 (2002).

${ }^{2}$ F. Capasso, C. Gmachl, D. L. Sivco, and A. Y. Cho, Phys. Today 55, 34 (2002).

${ }^{3}$ M. Beck, D. Hofstetter, T. Aellen, J. Faist, U. Oesterle, M. Ilegems, E. Gini, and H. Melchior, Science 295, 301 (2002).

${ }^{4}$ A. Evans, J. S. Yu, J. David, L. Doris, K. Mi, S. Slivken, and M. Razeghi, Appl. Phys. Lett. 84, 314 (2004).

${ }^{5}$ J. S. Roberts, R. P. Green, L. R. Wilson, E. A. Zibik, D. G. Revin, J. W. Cockburn, and R. J. Airey, Appl. Phys. Lett. 82, 4221 (2003).

${ }^{6}$ R. P. Green, A. Krysa, J. S. Roberts, D. G. Revin, L. R. Wilson, E. A. Zibik, W. H. Ng, and J. W. Cockburn, Appl. Phys. Lett. 83, 1921 (2003).

${ }^{7}$ C. Gmachl, A. Tredicucci, F. Capasso, A. L. Hutchinson, D. L. Sivco, J. N. Baillargeon, and A. Y. Cho, Appl. Phys. Lett. 72, 3130 (1998).

${ }^{8}$ A. A. Kosterev and F. K. Tittel, IEEE J. Quantum Electron. 38, 582 (2002).

${ }^{9}$ C. Sirtori, F. Capasso, J. Faist, A. L. Hutchinson, D. L. Sivco, and A. Y. Cho, IEEE J. Quantum Electron. 34, 1722 (1998).

${ }^{10}$ M. Troccoli, O. Assayag, L. Diehl, D. Bour, S. Corzine, G. Höfler, A. Tandon, D. Mars, and F. Capasso (unpublished). 